REGARDS

SUR L'ECONOMIE ALLEMAND

BULLETIN ECONOMIQUE DU CRRAC
Regards sur l'économie allemande

Bulletin économique du CIRAC

$104 \mid 2012$

Varia

\title{
Énergie : la bronca des milieux économiques
}

Isabelle Bourgeois

\section{OpenEdition}

Journals

Édition électronique

URL : http://journals.openedition.org/rea/4397

DOI : $10.4000 /$ rea. 4397

ISBN : 978-2-8218-1286-4

ISSN : 1965-0787

Éditeur

CIRAC

Édition imprimée

Date de publication : 13 avril 2012

Pagination : $31-32$

ISSN : 1156-8992

Référence électronique

Isabelle Bourgeois, «Énergie : la bronca des milieux économiques », Regards sur l'économie allemande [En ligne], 104 | avril 2012, mis en ligne le 17 avril 2012, consulté le 15 septembre 2020. URL : http:// journals.openedition.org/rea/4397

Ce document a été généré automatiquement le 15 septembre 2020

(C) CIRAC 


\title{
Énergie : la bronca des milieux économiques
}

\author{
Isabelle Bourgeois
}

1 «Le chaos de cette nouvelle politique énergétique menace l'emploi!». C'est sous ce titre que le quotidien BILD publiait le 3 avril 2012 une interview de Hans-Dietrich Driftmann. Dans cet entretien, le président de la Fédération des CCI allemandes (DIHK) résumait entre autres les principaux griefs des milieux économiques allemands envers les pouvoirs politiques. La compétitivité allemande dépend en effet largement du succès de la mise en œuvre de cette nouvelle politique décidée à la suite de l'avarie du réacteur de Fukushima, et plus encore de sa rapidité. Or «le pire, c'est que, dans ce changement de politique, rien n'est clair - sauf son objectif [i.e. la sortie du nucléaire d'ici 2022 (voir REA 101/2011) ; IB]. Si nous n'avançons pas assez vite dans le développement des infrastructures, cela nous coûtera croissance et emplois ».

\section{La question des infrastructures n'est pas résolue}

2 Et de fait, à part la fermeture de quelques centrales nucléaires et la réduction des subventions au secteur du photovoltaïque, peu d'éléments nouveaux sont intervenus depuis un an. Les réseaux de transport entre le nord de l'Allemagne où se concentre la production d'électricité éolienne et le sud, où se concentre la consommation industrielle, tardent à être modernisés, et le risque de black-out qui inquiète toujours l'autorité de régulation des réseaux (Bundesnetzagentur) reste présent. La situation est tendue au point que même le très sérieux quotidien Frankfurter Allgemeine Zeitung publiait le 16 mars un long papier d'humeur intitulé "Tous le pensent, personne ne le dit: la nouvelle politique énergétique est un échec». Pour toutes les critiques actuellement formulées, le cœur du problème réside dans les sous-capacités en matière d'infrastructures et la lenteur de leur extension. 


\section{Une « cacophonie » de politiques}

3 De fait, il n'y a pas en Allemagne une politique énergétique d'un seul tenant, mais au moins 17, étant donné la répartition des compétences afférentes entre plusieurs ministères à l'échelon fédéral, et l'autonomie des Länder qui définissent chacun sa propre politique de sortie du nucléaire et de promotion des renouvelables. Et, selon l'obédience de leurs gouvernements, ils se livrent à une véritable surenchère dans le mieux-disant écologique et proposent chacun son modèle. Restent les épineuses questions du stockage de l'électricité (source de conflits entre les impératifs de protection de la nature et ceux de compétitivité industrielle) et de l'aménagement des réseaux de transport qui soulève plusieurs problèmes: durée des procédures d'autorisation, opposition des riverains (syndrome du nimby, particulièrement prononcé outre-Rhin depuis les manifestations contre l'extension de la gare de Stuttgart: "Stuttgart 21 ») ou responsabilités peu claires en matière de financement public...

4 Pour les industriels, cette «cacophonie» (F.A.Z., 05-04-2012) et l'état prolongé d'incertitude qui s'ensuit et qui interdit toute planification, sont dramatiques. S'ils savent s'accommoder des changements de cap politiques, ils ne redoutent rien de plus que l'absence de prévisibilité.

\section{Des critiques de plus en plus pressantes...}

5 Et dès lors, depuis quelques mois, les critiques des milieux économiques se multiplient. D'abord très convenues, voire diplomatiques, comme les divers catalogues de mesures concrètes proposées par la Fédération des CCI allemandes (DIHK) ou la Fédération de l'industrie chimique $(\mathrm{VCI})$, ou encore cette prise de position de la Fédération de l'industrie BDI en date du 14 décembre 2011, par laquelle son vice-président appelle les pouvoirs publics à «ménager le tournant énergétique de manière à ce que la compétitivité mondiale de l'Allemagne n'en souffre pas et que soit préservé l'emploi industriel». Mais au fur et à mesure que perdurent les incertitudes, et dans le contexte médiatique du premier anniversaire de la sortie du nucléaire, le ton se fait plus pressant.

\section{... et un appel à la co-décision}

6 C'est ainsi que, le 3 avril, Klaus Engel, président de la Fédération VCI et PdG du groupe Evonik, publiait dans le quotidien Handelsblatt une tribune libre : "Pas comme ça!». Il résume lui aussi avec force les griefs de ses homologues et s'insurge: "aucun investisseur n'est prêt à investir durablement des capitaux dans un marché aussi politisé et dont les règles sont susceptibles de changer à quelques mois d'intervalle ». Mais comme toujours en Allemagne, sa critique se veut avant tout constructive. Il formule ainsi deux propositions. D'une part, et de toute urgence, « la nomination d'un coordinateur Energie au sein du gouvernement fédéral », ce qui permettrait de remédier au chaos des compétences. D'autre part, comme cette mesure ne couvre qu'un aspect, « il faut que la feuille de route nationale soit au préalable développée conjointement avec l'industrie ». Et il ajoute, se faisant l'écho de nombre d'acteurs économiques et experts: "Il s'agit de rien de moins que de définir un nouveau contrat social sur l'approvisionnement en énergie ». 
7 C'est bien là que le bât blesse. Si l'industrie partage l'idée d'une autre politique énergétique, elle ne souffre plus la précipitation avec laquelle avait été adoptée la sortie du nucléaire, et encore moins le conflit de moins en moins larvé entre visées écologiques et impératifs économiques mondiaux. Il en va de sa compétitivité et du rôle moteur qu'elle joue pour la croissance et l'emploi en Allemagne. Si elle est partante pour une 'révolution' énergétique, elle n'est pas prête à la subir, surtout sans avoir pu jouer le rôle institutionnel qui est le sien: celui de la co-décision et de la coresponsabilité sur un dossier aussi stratégique pour l'avenir du site Allemagne. IB

\section{INDEX}

Mots-clés : énergie, politique énergétique, infrastructure, écologie, politique de l'environnement, protection de l'environnement, industrie 